\title{
Effectiveness of social advertisements in promoting adoption of selected health and hygiene practices
}

\author{
Sumita Bhalla and Preeti Sharma
}

Received: 11.06.2020; Revised: 13.10.2020; Accepted: 28.10 .2020

See end of the paper for authors' affiliations Sumita Bhalla

Department of Home Science

Extension Education, SSM

College, Dinanagar (Punjab)

India

Email : simranbhalla54@gmail.

com
ABSTRACT : The present study was conducted with the objective to assess the effectiveness of social advertisements in promoting adoption of selected health and hygiene practices. The study was conducted in purposively selected two districts of Punjab, India i.e. Gurdaspur and Ludhiana. Total eight villages from four selected blocks of selected districts were randomly selected. From each of the selected village 20 rural women were selected randomly. So, in total 160 respondents made a sample for data collection. The most frequently telecasted five government sponsored social advertisements during the month of June, 2017 on Swach Bharat Abhiyan (Clean India campaign), use of ORS/Zinc during diarrhoea, pregnancy check-up, immunization and breast feeding were selected after consultation with experts. Data was collected using pre-tested structured interview schedule. The effectiveness of social advertisement was assessed in terms of adoption stages i.e. awareness, interest and adoption of health and hygiene practices. The findings revealed that the advertisement of Swach Bharat Abhiyan (Clean India campaign) helped 91.25 per cent respondents to adopt the practice of keeping the environment clean. Most of the respondents i.e. 83.13 per cent immunized their children below 5 years of age. Majority of the respondents $(66.38 \%)$ were at adoption stage of exclusive breast feeding of infants for first 6 months. Nearly half of the respondents (48.13\%) were at the interest stage of adopting the practice of check-up of pregnant women. Nearly two fifth of respondents (42.50\%) were at adoption stage of using ORS/Zinc during diarrhoea. It can be concluded that social advertisement plays a significant role in influencing people to adopt health and hygiene practices. It is suggested that more emphasis should be given to produce good social advertisement on different issues to promote adoption of better and improved health and hygiene practices.

KEY WORDS: Social advertisement, Adoption stages, Health, Hygiene practices, TV viewing behaviour, Effectiveness

- HOW TO CITE THIS PAPER : Bhalla, Sumita and Sharma, Preeti (2020). Effectiveness of social advertisements in promoting adoption of selected health and hygiene practices. Asian J. Home Sci., 15 (2) : 220-226, DOI: 10.15740/HAS/AJHS/15.2/220-226. Copyright@ 2020: Hind Agri-Horticultural Society. 